Bio - grafía. Escritos sobre la Biología y su Enseñanza. ISSN 2027-1034

Edición Extraordinaria. p.p. 1458 - 1462

Memorias del IX Encuentro Nacional de Experiencias en Enseñanza de la Biología y la Educación Ambiental. IV Congreso Nacional de Investigación en Enseñanza de la Biología.

\title{
TALLER: PERSPECTIVAS INTERPRETATIVAS INTER-RELACION AMBIENTE CULTURA..CULTURA AMBIENTE...
}

\section{INTERPRETATIVE PERSPECTIVES INTER-RELATIONS ENVIRONMENT CULTURE..CULTURE ENVIRONMENT ...}

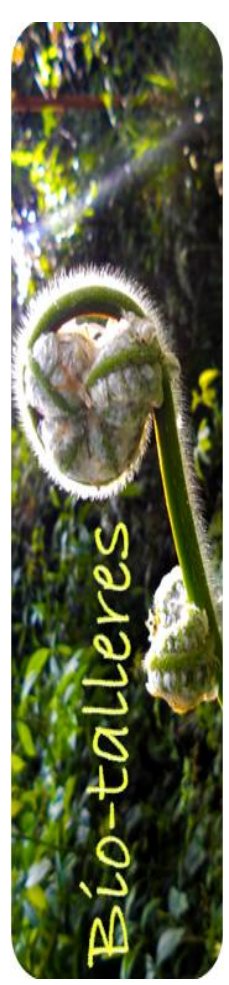

\section{Marco Tulio Peña Trujillo*}

\section{RESUMEN}

El taller se sitúa en el contexto contemporáneo de las emergentes dinámicas y realidades socioambientales, socioculturales y los retos investigativos y de adecuación de alternativas socioeducativas en línea de dichas dinámicas y realidades. El espacio de igual manera se dinamiza tomando como base la constitución de un sujeto experiencial, intersubjetivo en sus representaciones sociales de comprensión del mundo, en el caso particular integrados a la enseñanza de la biología, educación ambiental, perspectivas de la ecología social.

En otras palabras, mediante el ejercicio del taller se busca la motivación de comprensiones crítico-reflexivas en función de las interacciones posibles ambiente cultura, cultura ambiente, dando lugar como eje dinamizador, a las representaciones de los participantes desde una perspectiva intersubjetiva e interdisciplinaria en la construcción colectiva de interconocimientos.

Sucintamente a nivel de las habilidades investigativas el ejercicio brinda elementos de orden investigativo-interpretativo dentro de los procesos formativos y campos de acción, afines con la enseñanza de la biología y educación ambiental en los cuales se encuentren adscritos y/o relacionados los asistentes.

PALABRAS CLAVES: Inter-relación, ambiente, cultura,experiencia,sujeto, representación,interconocimiento.

\section{ABST ACT}

The workshop is situated in the contemporary context of the emerging socioenvironmental and socio-cultural dynamics and realities and the research and

\footnotetext{
* Licenciado en Biología. Mg. En Desarrollo Educativo y Social.Docente investigador. Profesor Ocasional Universidad Pedagógica Nacional. Facultad de Ciencia y Tecnología Departamento de Biología, Universidad Pedagógica Nacional (Colombia). Profesor Universidad Externado de Colombia. Facultad de Ciencias Sociales y Humanas. Programa Interacciones Multiculturales. Email: mpenat@pedagogica.edu.co
} 
Bio - grafía. Escritos sobre la Biología y su Enseñanza. ISSN 2027-1034

Edición Extraordinaria. p.p. $1458-1462$

Memorias del IX Encuentro Nacional de Experiencias en Enseñanza de la Biología y la Educación Ambiental. IV Congreso Nacional de Investigación en Enseñanza de la Biología.

adaptation challenges of socio-educational alternatives in line with these dynamics and realities. Space is likewise dynamized based on the constitution of an experiential subject, intersubjective in its social representations of understanding of the world, in the particular case integrated into the teaching of biology, environmental education, perspectives of social ecology.

In other words, through the exercise of the workshop we seek the motivation of criticalreflective understandings in terms of possible interactions between culture and environment culture, giving rise as a dynamic axis to the representations of participants from an intersubjective and interdisciplinary perspective in the Collective construction of inter-knowledge.

Succinctly at the level of investigative skills, the exercise provides elements of investigative-interpretive order within the formative processes and fields of action, related to the teaching of biology and environmental education in which the attendees are attached and / or related.

KEYWORDS: Interaction, environment, culture, experience, subject, representation, inter-knowledge.

\section{INTRODUCCIÓN}

La configuración de nuevos paradigmas acaecidos de las emergentes dinámicas y realidades sociombientales ${ }^{1}$, socioculturales ${ }^{2}$ y que traen consigo también retos contemporáneos a los que se enfrenta la investigación social y las perspectivas contemporaneas socioeducativas ${ }^{3}$, que se podría decir se muestran influidas también por las formas de representación social de la realidad particulares y diversas en la comprensión, concepción y habitar el mundo. En el caso particular integrados en los frentes epistémicos referidos con la enseñanza de la biología, educación ambiental, perspectivas de la ecología social; connotados en lo que se podría precisar como transdiciplinarios devenidos de dichos paradigmas emergentes.

En tal contexto, no menos importante se sitúa aquí también, el lugar de un sujeto constitutivo de experiencias propias de su condición humana sociocultural y de sus formas de relacionamientos, representaciones e interpretación del mundo (ambientes, naturaleza...), en otras palabras el sujeto "se sitúa y relaciona con el mundo según como lo concibe y/o representa".

\footnotetext{
1 (...) como las formas sinérgicas de correlación hombre/naturaleza, mediadas por significaciones simbólicas (cosmogonías), en donde lo natural se hace social y lo social se hace natural eza (Peña, 2013:30).

2 (...) como las formas de asociación mediadas por expresiones identitarias, representadas por significaciones integrales social mente (Peña, 2013:30).

3 Hace referencia a las formas deinterrelación social significadas en diferentes ambientes de expresión (familia, escuela, comunidad, grupo social...) las cuales constituyen expresiones integrales temporales espacial es que forjan el desarrollo humano, mediado por formas identitarias de asociación e integración necesariamente colectivas (Peña, 2013:30).
} 


\section{Bio - grafía. Escritos sobre la Biología y su Enseñanza. ISSN 2027-1034}

Edición Extraordinaria. p.p. 1458 - 1462

Memorias del IX Encuentro Nacional de Experiencias en Enseñanza de la Biología y la Educación Ambiental. IV Congreso Nacional de Investigación en Enseñanza de la Biología.

En este sentido la experiencia en el mundo de la vida del sujeto cobraría un importante sentido en las formas de representación e interpretación: "Está marcada fundamentalmente por las características, sensibilidades, pensamientos y emociones de los sujetos, los hombres y las mujeres que las viven. Así, las personas vivimos las experiencias con expectativas, sueños, temores, esperanzas, ilusiones, ideas e intuiciones. Las personas somos las que hacemos que ocurran esos procesos complejos y dinámicos; esos procesos, a su vez, nos marcan, nos impactan, nos condicionan, nos exigen, nos hacen ser. Las experiencias, son individuales y colectivas a la vez; las vivimos y nos hacen vivir; en definitiva, somos seres humanos en cuanto vivimos cotidiana y socialmente experiencias". Jara (2009; p.2).

Referido con lo anterior, en relación a la vida cotidiana esta entraría a constituirse: "(...) como escenario propiciatorio mediante el cual emergen, se crean y recrean los saberes pasa a constituirse en lo que se podría denominar las acciones y representaciones prácticas que los miembros de un determinado grupo social conservan y motivan a partir de su diario vivir o vida cotidiana, que su vez es contextualizada y particularizada por patrones y dinámicas socioculturales endógenas de los grupos sociales y que son legadas a partir de procesos de endoculturaciòn 0 transmisión cultural". Peña (2013,p.86).

Visto así desde la condición del sujeto experiencial desde su vida cotidiana, crea y recrea formas de representación de los ambientes desde sus múltiples formas de relacionamientos axiológicos como sociocognitivos asumidos estos últimos aquí como: “(...) constitutivos de los procesos mentales y axiológicos motivados y dinamizados mediante las relaciones sociales, significaciones culturales, repertorio natural, influyentes en la constitución del sujeto" (Peña, 2013:30).

En tal sentido, las miradas de dichos ambientes se muestran dispuestos desde diferentes configuraciones, desde los postualdos de Sauve (2009) y situando la reflexión en el taller, el ambiente no sería solamente aprehendido como un conjunto de elementos biofísicos que basta con abordarlos con objetividad y rigor para comprender mejor, para poder interactuar mejor. El cual corresponde a un medio de vida, en sus dimensiones históricas, culturales, políticas, económicas, estéticas dentro de otros.

Acorde con lo anterior desde la mirada interdisciplinaria y desde un sentido intercultural, se podría hacer énfasis también, al inter-conocimiento dispuesto en el panorama de debates de la disyuntiva saber/conocimiento, referido por De Sousa Santos (2009), quien postula acerca de la ecología de saberes desde donde se concibe la posibilidad de propiciar el dialogo entre el saber científico y el humanístico que la universidad produce, implicando una amplia gama de acciones de valoración, tanto del conocimiento científico como de otros conocimientos prácticos compartidos por investigadores sirviendo para la creación de comunidades epistémicas más amplias que conviertan a la universidad en un espacio público de interconocimiento.

Sucintamente desde las perspectivas expuestas, los participantes del taller tienen la posibilidad de situar de forma reflexiva el lugar de su experiencia y configuración de conocimientos interdisciplinares referidos para el caso desde las representaciones e 
Bio - grafía. Escritos sobre la Biología y su Enseñanza. ISSN 2027-1034

Edición Extraordinaria. p.p. 1458 - 1462

Memorias del IX Encuentro Nacional de Experiencias en Enseñanza de la Biología y la Educación Ambiental. IV Congreso Nacional de Investigación en Enseñanza de la Biología.

interpretaciones vistas a partir de las inter-relaciones ambiente cultura, cultura ambiente como se ha venido exponiendo.

\section{PROPÓSTOS}

- Propiciar reflexiones epistémicas sobre el lugar del sujeto como constructor colectivo de interconocimientos posibles situados en la enseñanza de la biología y la educación ambiental.

-Posibilitar comprensiones desde el posicionamiento crítico-reflexivo entorno a la interacción ambiente cultura, cultura ambiente, tomando como fundamento dinamizador las representaciones e interpretaciones experienciales de los participantes del taller desde la perspectiva intersubjetiva e interdisciplinaria.

-Aportar elementos de orden investigativo-interpretativo y ético dentro de los procesos formativos y campos de acción afines con la enseñanza de la biología y educación ambiental en los cuales se encuentren adscritos o relacionados los participantes.

\section{ASPECTOS PROCEDIMENT ALES:}

Como se ha venido indicando el taller se sitúa en la con construcción colectiva de interconocimiento en la mirada intersubjetiva interdisciplinaria sobre las representaciones referidas con el ambiente cultura, cultura ambiente interpretados a partir de un ejercicio hermenéutico. Por tanto se espera que el perfil de los participantes sea a fin a los estudios sociales, enseñanza de la biología, de educación y gestiones ambientales y relacionadas. Es de indicar que dentro del ejercicio se tienen en cuenta las consideraciones éticas tanto en el desarrollo, como en el tratamiento de la información devenida del proceso.

El taller se dinamiza a partir de cuatro momentos transversales:

1) Contexto epistémico y socialización de la dinámica del ejercicio

2) Conformación de grupos interdisciplinarios (de acuerdo al número de participantes, perfiles, otros.

3) Construcción de matrices interpretativas a partir de los conceptos: ambiente, cultura, interacción ambiente cultura y emergentes.

4) Socialización por grupos de las producciones interpretativas. Plenaria orientada a partir de los aportes del ejercicio a partir de la fundamentación conceptual, ejercicio investigativo, motivación de actitudes personales como profesionales, otras emergentes.

Materiales: Equipos de proyección, ordenadores, libreta de notas. 
Bio - grafía. Escritos sobre la Biología y su Enseñanza. ISSN 2027-1034

Edición Extraordinaria. p.p. 1458 - 1462

Memorias del IX Encuentro Nacional de Experiencias en Enseñanza de la Biología y la Educación Ambiental. IV Congreso Nacional de Investigación en Enseñanza de la Biología.

\section{BIBLIOGRAFÍA}

Jara, O. (2009). La sistematización de experiencias y las corrientes innovadoras del pensamiento latinoamericano - Una aproximación histórica. Diálogo de Saberes №. 3 , 118- 129 .

Peña, M.T. (2013). Construcción de subjetividades políticas de niñas, niños y jóvenes quechua hablantes, en el contexto de la experiencia Comunidades Andinas Educativas en los Andes centrales del Perú: Un referente de educación alternativa. Bogotá:

Peña, M.T.(2012). Taller de interpretación hermenéutica (Manuscrito no publicado). CINDE-UPN.Bogotá.

Santos, B. (2009) .Una Epistemología del Sur. CLACSO. Consejo Latino Americano de Ciencias Sociales. Buenos Aires, Argentina.

Sauvè, Luciè. (2009). Una Cartografía de Corrientes en Educación Ambiental. Cátedra de Investigación de Canadá en Educación Ambiental. Canadá. Universidad de Quebec. Montreal. 